\title{
Development of a Decision Support Framework for Health Beverage Flavouring for the Ageing Society Using Artificial Neural Network
}

\author{
Athakorn Kengpol, Jakkarin Klunngien, and Sopida Tuammee
}

\begin{abstract}
The objective of this research is to select health beverage flavour appropriate for the ageing people with the aid of a decision support framework by using the artificial neural network. The decision support framework's role is to gather information between consumers and manufacturers. The framework has the capability to compile the collected data and form the suitable model for selecting beverage flavouring of the products. In order to identify the preference of consumer, the artificial neural network has been applied to classify the beverage preference, i.e. taste, colour and odour of health beverages as well as the consumer groups. The questionnaire is used to gather the preference for taste, colour and odour from consumer groups which are separated into four groups such as the gender (male or female), age (60-65 years or over 65 years) health condition (healthy or unhealthy) and symptoms. The results of this research can benefit to consumers and manufacturers. The consumers can know the most preferred health beverage. In addition, the manufacturers can produce products that can match the consumer's preference.
\end{abstract}

Index Terms-Decision support system, artificial intelligence, artificial neural network, ageing society.

\section{INTRODUCTION}

Nowadays, the situation of the world population age structure is changing progressively with the population getting older and the child population declining. Consequently, the world becomes an ageing society. In Thailand, demographics show that a 2015 population of 68.66 million, a $2.11 \%$ increased from a 2010 population of 67.21 million. The elderly are likely to increase from 8.70 million in 2010 to 10.74 million in 2015 or increased by $18.99 \%$. As a result, the proportion of the elderly population in Thailand will be $15.64 \%$, leading to an ageing society [1]. For this reason, the ageing populations are concerned about their health [2]. Therefore, the demand for the health food and drink is increasing. Health awareness now focuses on individual feeling which affects purchasing and consuming of healthy food and drink behavior [3]. By evaluating consumer acceptance of healthy food and beverages, consumers have focused on taste, odour and texture. Furthermore, consumers

Manuscript received September 10, 2018; revised November 22, 2018.

Athakorn Kengpol and Jakkarin Klunngien are with Advanced Industrial Engineering Management Systems Research Center, Department of Industrial Engineering, Faculty of Engineering, King Mongkut's University of Technology North Bangkok, Bangkok, Thailand (e-mail: athakorn@kmutnb.ac.th, jakkarinkl@gmail.com).

Sopida Tuammee is with Department of Information and Production Technology Management, College of Industrial Technology, King Mongkut's University of Technology North Bangkok, Bangkok, Thailand (e-mail: sopida.t@ cit.kmutnb.ac.th). normally select their favourite beverage which is advised as good for health [4].

Due to different demands from consumers, the identification of flavours (taste, colour and odour) of health beverages can be difficult. This research proposes a decision support framework (DSF) with multi-layer perceptron neural network (MLPNN) to classify and select health beverage flavour (taste, colour and odour) which is suitable for the elderly.

\section{LITERATURE REVIEW}

\section{A. Decision Support Framework}

A decision support framework (DSF) is an information technology that supports decision-making activities. DSF supports the management, operations and organisation planning and help decision maker can make decisions about problems [5]. A decision-making process would be affected by the individual performance as the decision maker, their preferences and the criteria used to make the decision [6]. Therefore, DSF is a computer software system which can be implied in helping the decision makers in order to use models and data to solve the problems [7].

\section{B. Artificial Neural Network}

Modeling techniques which use artificial neural network (ANN) have been widely used and successfully over the last years [8]. ANN is another widely used tool in the classification. Such a model is developed of the problem to be solved. Hence, decision support system based on artificial neural network has been widely applied due to its simplicity and scalability [9]-[11]. Specifically, in classifying the complex of customer demand, ANN has been applied for classifying of the taste concentration with back-propagation algorithm (BP) [12]. After that, artificial intelligence system (AI) was developed with neural network algorithm through multi-layer perceptron architecture (MLPNN) with supervised learning by BP to classify the fragrance notes. Furthermore, ANN also has an ability to explore complex hidden patterns based on an involved input requirement on complex fragrance notes [13].

ANN is a computation method that simulates the work of biological neurons. The neurons are arranged in a defined structure which is created by the layer and defined by the number of neurons [14]. The advantage of ANN is learning for estimating information that has never been seen. At present, ANN is used in several ways such as forecasting, classification, pattern recognition and robotic control, etc. In 
this research, MLPNN with supervised learning is used to classify the health beverages flavours (taste, colour and odour) that are consumer's needs.

\section{Evaluation the Model}

Cross-validation [15] is a measurement of evaluating the performance of a forecasting model and statistical analysis will generalise to datasets. The datasets are divided into several parts such as $\mathrm{K}$-fold cross-validation ( $\mathrm{K}$ is sub-samples). After that, one of the datasets is used as the model's performance evaluation with confusion matrix. The confusion matrix contains information about actual and forecasted form the classification model [16].

Accuracy is the value that the model can forecast accurately.

$$
\text { Accuracy }=\sum_{i=1}^{n} Y_{i i} / \sum_{i=1}^{n} \sum_{j=1}^{n} Y_{i j}
$$

where $Y_{i j}$ is the number of samples actually belong to class $A_{i}$, which is classified by class $A_{j}$.

Precision is the value that the model forecasts is correct.

$$
\text { Precision }_{i}=Y_{i i} / \sum_{k=1}^{n} Y_{k i}
$$

Recall is a measure of the forecasted model ability.

$$
\operatorname{Recall}_{i}=Y_{i i} / \sum_{k=1}^{n} Y_{i k}
$$

\section{Methodology}

In order to obtain the decision support framework (DSF), the steps of this research are illustrated in Fig. 1, which consists of gathering the data, system designing, programming and testing, finally verifying and validating.

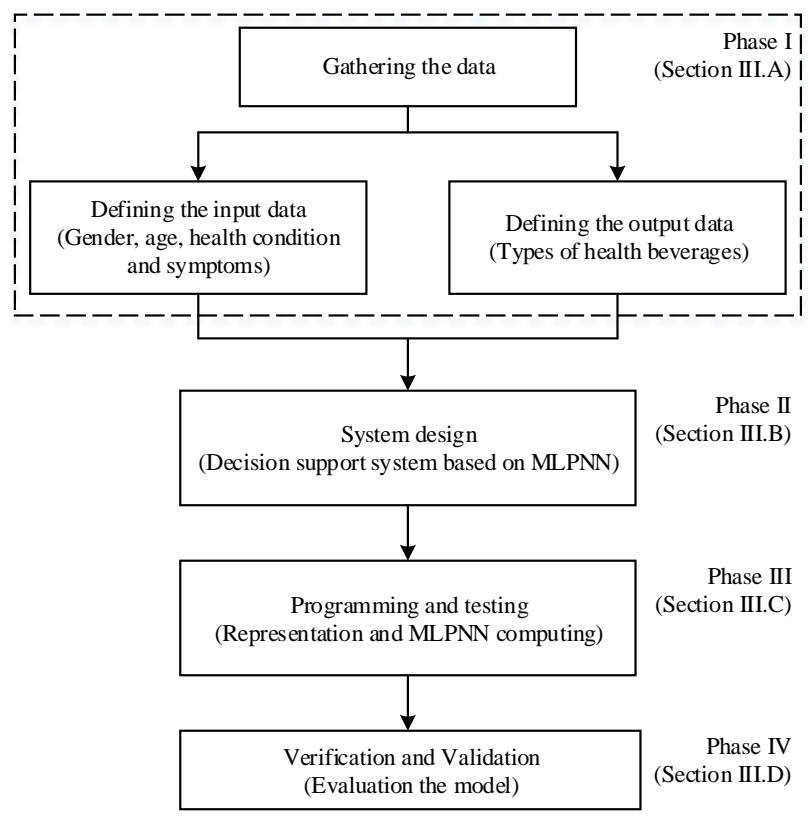

Fig. 1. DSF concept for health beverages flavouring.

\section{A. Gathering the Data}

Questionnaires were used to obtain the preferences of the 200 Thai elderly on health beverages flavour. The samples were divided into four groups, which were gender (male or female), age (60-65 or over 65 years), health condition (healthy or unhealthy) and symptoms of the elderly. Those symptoms related to the common problems elderly, which are Cardiovascular disease, Central nervous system, Gastrointestinal system, Urinary system, Endocrine system, Musculoskeletal system, Seeing and Hearing, and others. Then, the types of health beverages were selected from the properties that mitigate those symptoms and was investigate by experts. The beverages are Lingzhi drink, Lingzhi drink with honey, Germinated brown hom nin rice drink with cereal, Mangosteen juice, Mangosteen juice with longkong, Pomegranate juice, Passion juice, and Passion juice with gac fruit

\section{B. The Decision Support Framework Designing}

The decision support framework (DSF) should have three main components, that are user interface, inference engine for decision making and database for storing the data and training the system [13]. Fig. 2 shows the DSF model based on MLPNN.

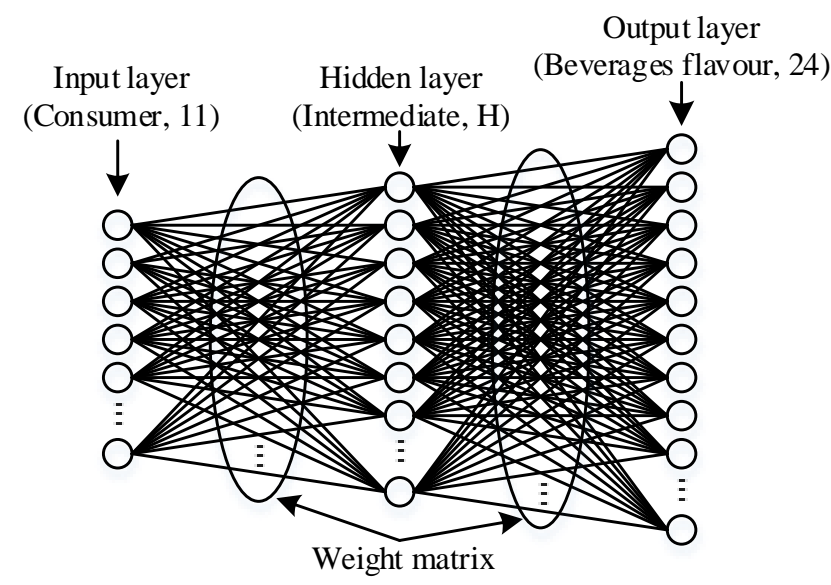

Fig. 2. The DSF model based on MLPNN.

\section{1) User interface and database designing}

The decision support framework program was designed by using HTML which features the input form for the user and shows the results of decision making. The PHP was developed to train the system by MLPNN through the data which was recorded in MySQL database. This framework was used to classify health beverage preference to the elderly. The welcome page for user interface shows in Fig. 3, which divides into consumer section, manufacturer section and administrator.

\section{2) The artificial neural network designing}

A suitable and simple structure to solve the classification problem employed a multi-layer perceptron neural network (MLPNN) which is a back-propagation algorithm (BP). The structure consists of the first layer (called input layer), the second layer (called hidden layer) and the third layer (called output layer). 


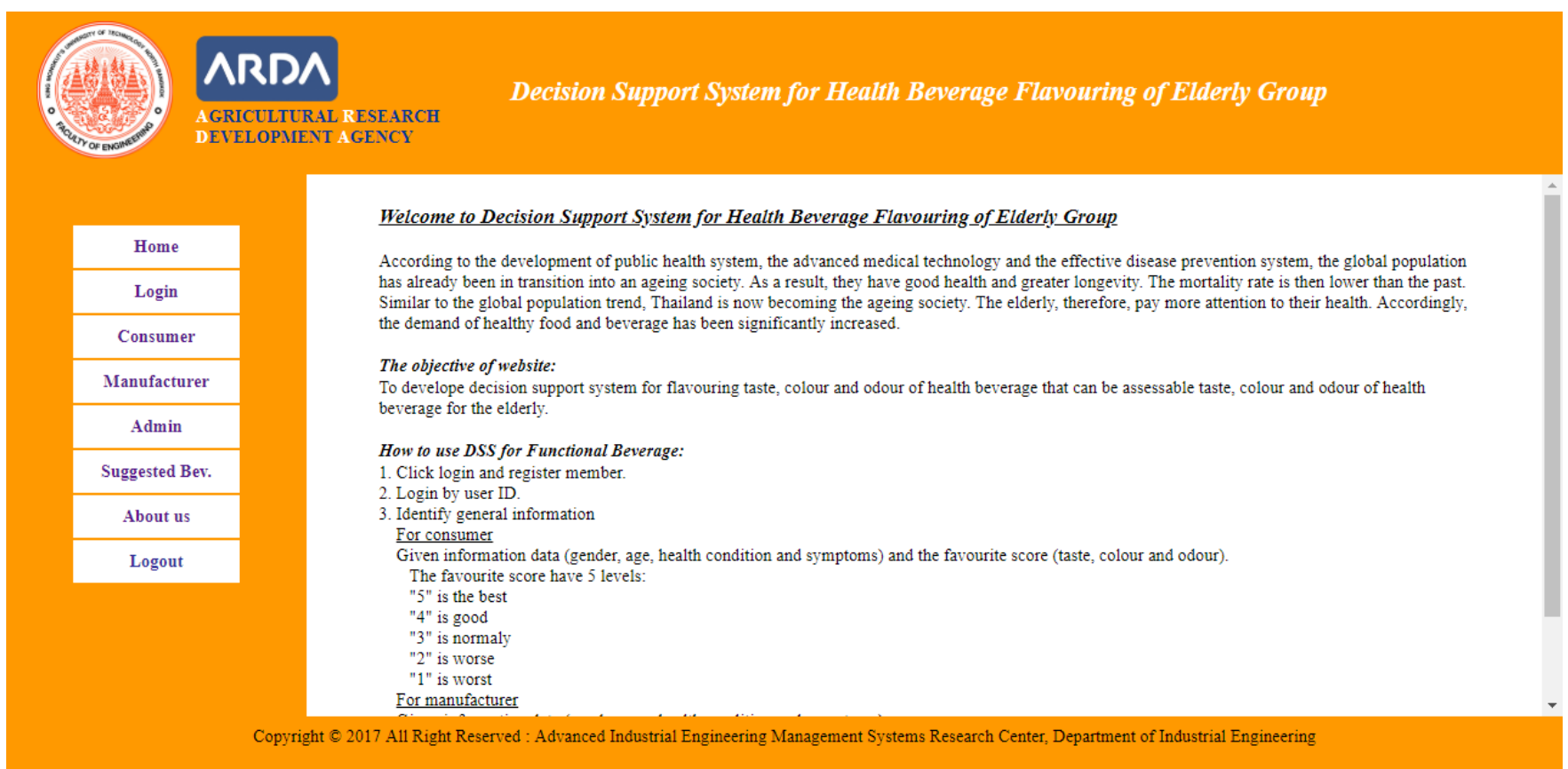

Fig. 3. Welcome page for DSF program, developed by the authors.

The number of neurons in the input layer should have 11 nodes (refer to the number of elderly groups), the number of neurons in the output layer should have 24 nodes (refer to the number of flavouring beverages) and the number of neurons in the appropriate hidden layer is the neurons number which is the lowest mean square error (MSE) as shown in (4). The function used to determine the output signal is called the transfer function or activation function which is shown in (5). The training function for consumer health beverage preferences is the back-propagation algorithm which can adjust the weight matrix as shown in (6) to (9).

Mean square error (MSE)

$$
M S E=\frac{1}{N} \sum_{n=1}^{n}\left[e_{j}(n)\right]^{2}
$$

where $N$ is the number of neurons in output layers.

Transfer function

$$
Y=\varphi(v)=1 /(1+\exp (-v))
$$

where $Y$ is output value, $\varphi$ is transformation function and $v$ is sum of weights.

Weight update

$$
\begin{aligned}
W_{j i}^{(l)}(n+1)= & W_{j i}^{(1)}(n)+\alpha\left[W_{j i}^{(1)}(n)-W_{j i}^{(1)}(n-1)\right](6) \\
& +\eta \delta_{j}^{(l)}(n) y_{j}^{(l-1)}(n)
\end{aligned}
$$

whereas

$$
\begin{gathered}
e_{j}(n)=d_{j}(n)-o_{j}(n) \\
\delta_{j}^{(L)}(n)=e_{j}(n) o_{j}(n)\left[1-o_{j}(n)\right] \\
\delta_{j}^{(l)}(n)=y_{j}(n)\left[1-y_{j}(n)\right] \sum \delta_{k}^{(l+1)}(n) W_{k j}^{l+1}(n)
\end{gathered}
$$

where $\mathrm{W}_{\mathrm{ji}}$ is weight matrix, $\mathrm{n}$ is learning iteration (epoch), $\mathrm{l}$ is first and second (hidden) layer, $\alpha$ is learning rate, $\eta$ is momentum constant, $\delta_{\mathrm{j}}$ is slope at a layer, e is error, $\mathrm{d}$ is desire output, o is computation output, $\mathrm{L}$ is output layer, $\mathrm{y}$ is output at a layer and $\delta_{\mathrm{k}}$ is previous slope.

According to input, hidden and out layer can simulate the structure of the MLPNN in Fig. 4.

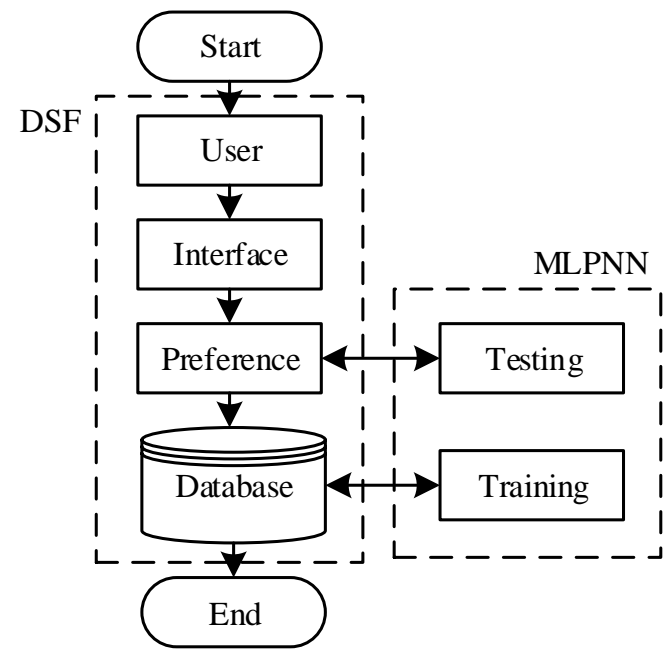

Fig. 4. MLPNN model for health beverages flavouring.

\section{Programming and Testing}

Within the DSF program, the buttons should be tested to show that they function correctly. For example, user interface, Fig. 5 shows consumer section page for input the data to DSF program.

After that, the number of nodes in the hidden layer was determined by the number of neurons that had the lowest MSE with MLPNN algorithm as shown in Fig. 6. The appropriate neural network structure in this research had 11 input layer nodes, 30 hidden layer nodes and 24 output layer nodes (11-30-24). The MSE in 30 hidden layer nodes was 0.01569. 
Part I:
Please, identify your general information.

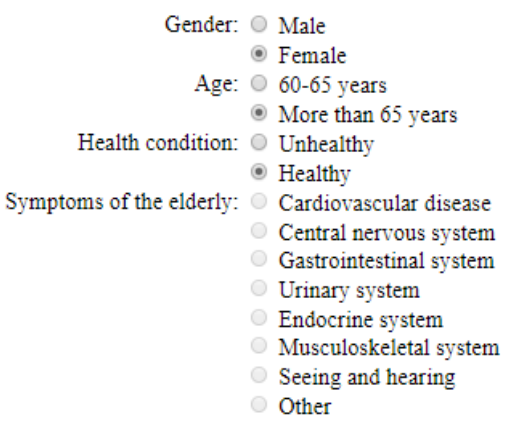

Part II:

Please score of taste, colour and odour for your preference of health beverage.

\begin{tabular}{|c|c|c|c|}
\hline & Taste: & Colour: & Odour: \\
\hline Lingzhi drink & $4 \mathbf{V}$ & $4 \mathbf{V}$ & $4 \mathbf{V}$ \\
\hline Lingzhi drink with honey & $4 \mathbf{V}$ & $4 \mathbf{V}$ & $4 \mathbf{V}$ \\
\hline Germinated brown hom nin rice drink with cereal & $4 \mathbf{V}$ & $4 \mathbf{v}$ & $4 \mathbf{V}$ \\
\hline Mangosteen juice & $4 \mathbf{V}$ & $4 \mathbf{V}$ & $4 \mathbf{~ V}$ \\
\hline Mangosteen juice with longkong & $4 \mathbf{V}$ & $4 \mathbf{V}$ & $4 \mathbf{v}$ \\
\hline Pomegranate juice & $4 \mathbf{V}$ & $4 \mathbf{~ V}$ & $4 \mathbf{~ V ~}$ \\
\hline Passion juice & $5 \mathrm{~V}$ & $5 \mathrm{v}$ & $5 \mathrm{~V}$ \\
\hline Passion juice with gac fruit & $4 \mathbf{V}$ & $4 \mathbf{V}$ & $4 \mathbf{~ V ~}$ \\
\hline
\end{tabular}

Fig. 5. The DSF program (consumer section page).

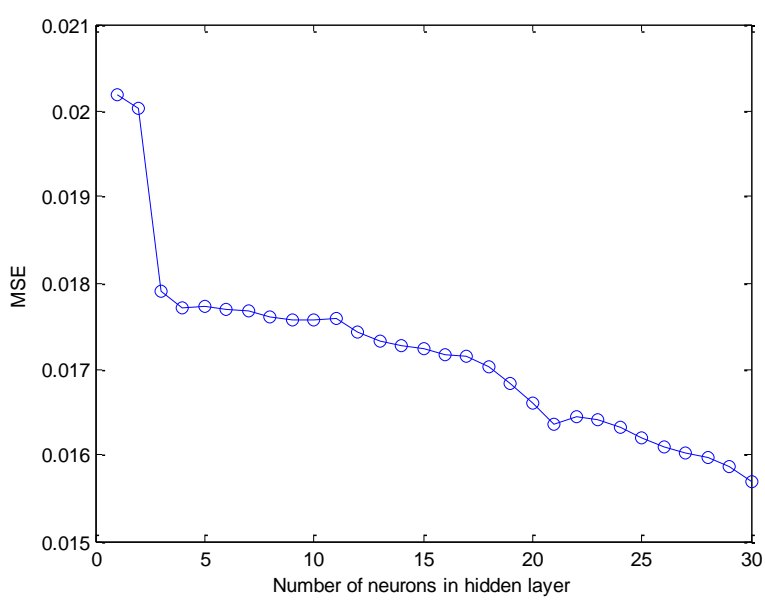

Fig. 6. MSE versus number of neurons in the hidden layer.

\section{Verification and Validation}

K-fold cross-validation is used to validating the MLPNN model. This research, $\mathrm{K}$ is 10 (10-fold cross-validation) [15] then the datasets are divided into 10 sub-samples. A single sub-sample is considered the validation data for the model testing and the K-1 sub-samples are used to training the data. The process is repeated $\mathrm{K}$ times (10 times) and $\mathrm{K}$ sub-samples used exactly as the validation data.

The results from 10-fold cross-validation are shown in the confusion matrix (Table IV). From the Table IV, the results show the forecasting data that are correctly and incorrectly. After that, the equation (1) and (2) are used to the computing recall and precision of each class of the forecasting data (Lingzhi drink with honey, Mangosteen juice, Mangosteen juice with longkong, Passion juice, and Passion juice with gac fruit). Finally, the equation (3) is used to the computing accuracy form the overall class. The results of validating the MLPNN model are shown in Table I. The evaluating of the model, the average recall is $78.87 \%$, the average precision is $82.01 \%$, and the accuracy is $79.50 \%$.

TABLE I: PERFORMANCE OF THE MLPNN MODEL

\begin{tabular}{|c|c|c|c|}
\hline Class & $\begin{array}{c}\text { Recall } \\
(\%)\end{array}$ & $\begin{array}{c}\text { Precision } \\
(\%)\end{array}$ & $\begin{array}{c}\text { Accuracy } \\
(\%)\end{array}$ \\
\hline Lingzhi drink with honey & 100.00 & 100.00 & 79.50 \\
\hline Mangosteen juice & 55.00 & 68.75 & \\
\hline Mangosteen juice with longkong & 66.67 & 90.32 & \\
\hline Passion juice & 87.23 & 83.67 & \\
\hline Passion juice with gac fruit & 85.37 & 67.31 & \\
\hline
\end{tabular}

Verification of this research was conducted by using a single case for system training in order to determine the convergence of data. The input data was general information from the elderly for example gender is female, aged over 65 years, health condition is healthy (if the user picks on healthy, cannot picks on type of the symptoms). The output data (target data) is the score of preference in the flavour of beverages (for this example set the highest rating for passion juice). The test results are shown in Table V.

From Table V, the values in rows Y19 (taste of passion juice), Y20 (colour of passion juice) and Y21 (odour of passion juice) converged to one, which is the target value, when the epochs increased and the MSE decreased. This confirmed that the system had a correct computation.

\section{RESULTS}

This research collected the data from the elderly northern, northeastern, southern, and central in Thailand by the questionnaire. The sample size is 200 samples. Data from the 
questionnaire are shown in Table II. The results show that $75.5 \%$ of the samples are unhealthy. The symptoms found in the samples are Musculoskeletal system, Endocrine system, and Cardiovascular disease, respectively.

TABLE II: The Details of Collecting DAta

\begin{tabular}{|c|c|c|c|}
\hline No. & \multicolumn{2}{|c|}{ Description } & Percentage \\
\hline \multirow[t]{2}{*}{1} & \multirow[t]{2}{*}{ Gender } & Male & 50.0 \\
\hline & & Female & 50.0 \\
\hline \multirow[t]{2}{*}{2} & \multirow[t]{2}{*}{ Age } & $60-65$ years & 48.5 \\
\hline & & Over 65 years & 51.5 \\
\hline \multirow[t]{2}{*}{3} & \multirow[t]{2}{*}{ Health condition } & Healthy & 24.5 \\
\hline & & Unhealthy & 75.5 \\
\hline \multirow[t]{8}{*}{4} & \multirow[t]{8}{*}{ Symptoms } & Cardiovascular disease & 23.0 \\
\hline & & Central nervous system & 1.0 \\
\hline & & Gastrointestinal system & 1.0 \\
\hline & & Urinary system & 1.0 \\
\hline & & Endocrine system & 24.0 \\
\hline & & Musculoskeletal system & 25.0 \\
\hline & & Seeing and hearing & 23.0 \\
\hline & & Other & 2.0 \\
\hline
\end{tabular}

The program was then implemented for a case study. In the beginning, input the data (in this example were female aged over 65 years and healthy) was used to classifying favorite beverage by consumer group (for this example set the highest rating for Passion juice). Next, consumer preference data was stored in the database to be used for decision making. The program results of favourites beverage by the consumer (personal) were then compared to the overall favorites beverage (shown in Table III).

TABLE III: OUtPut Form OF PERSONAL AND OVERALl PREFERENCE

\begin{tabular}{lcc}
\hline \hline Taste & $\begin{array}{c}\text { Health beverage for } \\
\text { consumer }\end{array}$ & $\begin{array}{c}\text { Recommended health } \\
\text { beverage }\end{array}$ \\
\hline Colour & Passion juce & Mangosteen juice \\
\hline Odour & Passion juce & Mangosteen juice \\
\hline \hline
\end{tabular}

The results from the data collection can be divided into eight groups: male aged 60-65 years and unhealthy, male aged 60-65 years and healthy, male aged over 65 years and unhealthy, male aged over 65 years and healthy, female aged 60-65 years and unhealthy, female aged 60-65 years and healthy, female aged over 65 years and unhealthy, and female aged over 65 years and healthy. In Table VI shows the most preferred health beverage for each sample. In addition, it shows the recommended healthy beverages according to the group of symptoms based on the nutrient of beverages.

\section{CONCLUSION AND RECOMMENDATION}

The resulted network architecture for classification of health beverages has 11 input layer nodes, 30 hidden layer nodes and 24 output layer nodes which were 100 epochs. MSE is 0.01569 . The evaluated performance of the model with 10-fold cross-validation and confusion matrix, accuracy is $79.50 \%$. The program can classify health beverages by consumer preferences successfully. Across manufacturer section, a variety of beverage flavouring in different products that make it a difficult and complicated task to identify the customer needs. Therefore, the objective of this research is to develop and design the decision support framework (DSF) in order to assess customer satisfaction on beverage flavouring by the DSF software.

For future study, consumers' preferences in large quantities should be performed but may take a long time when training. This is because of DSF design MLPNN by using a supervised learning method which allows a more accurate and appropriate result with a large scale data, and this is the reason DSF have to compare the output value and MSE versus epochs in Table V. Moreover, modifying the value of other variables such as learning rate can also affect the time of training.

\section{APPENDIX}

TABLE IV: PERFORMANCE OF THE MLPNN MODEL IN CONFUSION MATRIX

\begin{tabular}{|c|c|c|c|c|c|c|}
\hline & & \multicolumn{5}{|c|}{ Actual } \\
\hline & & $\begin{array}{c}\text { Lingzhi drink } \\
\text { with honey }\end{array}$ & Mangosteen juice & $\begin{array}{c}\text { Mangosteen juice } \\
\text { with longkong }\end{array}$ & Passion juice & $\begin{array}{l}\text { Passion juice } \\
\text { with gac fruit }\end{array}$ \\
\hline \multirow[t]{4}{*}{ Forecast } & $\begin{array}{l}\text { Lingzhi drink } \\
\text { with honey }\end{array}$ & 3 & & & & \\
\hline & Mangosteen juice & & 11 & & 4 & 1 \\
\hline & $\begin{array}{l}\text { Mangosteen juice } \\
\text { with longkong }\end{array}$ & & & 28 & 2 & 1 \\
\hline & $\begin{array}{l}\text { Passion juice } \\
\text { with gac fruit }\end{array}$ & & 9 & 2 & 6 & 35 \\
\hline
\end{tabular}

TABLE V: The CONVERGENCE OF SAMPLE DATA USED TO TEST THE PROGRAM

\begin{tabular}{|c|c|c|c|c|c|c|c|c|c|c|c|}
\hline \multicolumn{2}{|c|}{ Test } & 10 & 20 & 30 & 40 & 50 & 60 & 70 & 80 & 90 & 100 \\
\hline Y1 & 0.8 & 0.75175 & 0.79090 & 0.79782 & 0.79941 & 0.79971 & 0.79982 & 0.79980 & 0.79981 & 0.79981 & 0.79980 \\
\hline Y2 & 0.8 & 0.74131 & 0.78773 & 0.79740 & 0.79961 & 0.80003 & 0.80018 & 0.80015 & 0.80013 & 0.79996 & 0.79984 \\
\hline Y3 & 0.8 & 0.75074 & 0.79089 & 0.79787 & 0.79941 & 0.79969 & 0.79973 & 0.79976 & 0.79978 & 0.79982 & 0.79980 \\
\hline Y4 & 0.8 & 0.75117 & 0.79265 & 0.79881 & 0.80011 & 0.80026 & 0.80042 & 0.80041 & 0.80033 & 0.80022 & 0.80019 \\
\hline Y5 & 0.8 & 0.75782 & 0.79262 & 0.79872 & 0.79997 & 0.80019 & 0.80016 & 0.80018 & 0.80012 & 0.79995 & 0.79986 \\
\hline Y6 & 0.8 & 0.76786 & 0.79578 & 0.79899 & 0.79968 & 0.79983 & 0.79982 & 0.79982 & 0.79984 & 0.79984 & 0.79982 \\
\hline Y8 & 0.8 & 0.75730 & 0.79081 & 0.79766 & 0.79933 & 0.79983 & 0.79983 & 0.79984 & 0.79984 & 0.79984 & 0.79983 \\
\hline
\end{tabular}


TABLE V: The Convergence of SAmple Data Used to Test The Program (Cont.)

\begin{tabular}{|c|c|c|c|c|c|c|c|c|c|c|c|}
\hline \multicolumn{2}{|c|}{ Epochs } & 10 & 20 & 30 & 40 & 50 & 60 & 70 & 80 & 90 & 100 \\
\hline Y9 & 0.8 & 0.75352 & 0.79184 & 0.79787 & 0.79941 & 0.79983 & 0.79985 & 0.79991 & 0.79995 & 0.79992 & 0.79987 \\
\hline Y10 & 0.8 & 0.99827 & 0.82359 & 0.80556 & 0.80092 & 0.79989 & 0.79980 & 0.79984 & 0.79981 & 0.79983 & 0.79986 \\
\hline Y11 & 0.8 & 0.84424 & 0.81890 & 0.80464 & 0.80076 & 0.79995 & 0.79981 & 0.79983 & 0.79983 & 0.79983 & 0.79985 \\
\hline Y12 & 0.8 & 0.81883 & 0.80854 & 0.80210 & 0.80024 & 0.79976 & 0.79967 & 0.79963 & 0.79967 & 0.79977 & 0.79983 \\
\hline Y13 & 0.8 & 0.99948 & 0.99883 & 0.80810 & 0.80240 & 0.80062 & 0.80015 & 0.80014 & 0.80018 & 0.80016 & 0.80016 \\
\hline Y14 & 0.8 & 0.84606 & 0.82408 & 0.80789 & 0.80229 & 0.80065 & 0.80015 & 0.80015 & 0.80010 & 0.80006 & 0.80002 \\
\hline Y16 & 0.8 & 0.75189 & 0.79118 & 0.79840 & 0.80007 & 0.80033 & 0.80035 & 0.80020 & 0.80017 & 0.80017 & 0.80018 \\
\hline Y17 & 0.8 & 0.74744 & 0.78991 & 0.79821 & 0.79994 & 0.80023 & 0.80020 & 0.80018 & 0.80019 & 0.80019 & 0.80017 \\
\hline Y18 & 0.8 & 0.74442 & 0.79133 & 0.79947 & 0.80084 & 0.80084 & 0.80068 & 0.80049 & 0.80040 & 0.80019 & 0.80018 \\
\hline Y19 & 1 & 0.90397 & 0.92702 & 0.93846 & 0.94602 & 0.95141 & 0.95552 & 0.95882 & 0.96156 & 0.96386 & 0.96584 \\
\hline Y20 & 1 & 0.88795 & 0.91973 & 0.93448 & 0.94381 & 0.95022 & 0.95492 & 0.95854 & 0.96140 & 0.96374 & 0.96569 \\
\hline Y21 & 1 & 0.89710 & 0.92361 & 0.93661 & 0.94505 & 0.95093 & 0.95535 & 0.95883 & 0.96166 & 0.96400 & 0.96599 \\
\hline Y22 & 0.8 & 0.99784 & 0.81083 & 0.80588 & 0.80288 & 0.80158 & 0.80103 & 0.80079 & 0.80067 & 0.80054 & 0.80050 \\
\hline Y24 & 0.8 & 0.84790 & 0.82704 & 0.81035 & 0.80367 & 0.80156 & 0.80089 & 0.80067 & 0.80050 & 0.80049 & 0.80046 \\
\hline \multicolumn{2}{|c|}{ MSE } & 0.02125 & 0.01781 & 0.01618 & 0.01605 & 0.01597 & 0.01588 & 0.01580 & 0.01574 & 0.01570 & 0.01569 \\
\hline
\end{tabular}

TABLE VI: THE RESULTS OF BEVERAGE PREFERENCE AND RECOMMENDATION FOLLOW THE CONSUMER GROUPS

\begin{tabular}{|c|c|c|c|c|}
\hline \multirow{2}{*}{ Consumer groups } & \multicolumn{3}{|c|}{ "The most preferred health beverage by consumer group } & \multirow{2}{*}{$\begin{array}{c}\text { Beverage recommended } \\
\text { (by symptoms) }\end{array}$} \\
\hline & Taste & Colour & Odour & \\
\hline $\begin{array}{l}\text { Male } \\
\text { Age 60-65 years } \\
\text { Unhealthy }\end{array}$ & Passion juice & Passion juice & Passion juice & $\begin{array}{l}\text {-Lingzhi drink } \\
\text {-Germinated brown hom nin rice drink } \\
\text { with cereal } \\
\text {-Passion juice }\end{array}$ \\
\hline $\begin{array}{l}\text { Male } \\
\text { Age 60-65 years } \\
\text { Healthy }\end{array}$ & Passion juice & $\begin{array}{l}\text { Mangosteen juice with } \\
\text { longkong }\end{array}$ & $\begin{array}{l}\text { Passion juice with gac } \\
\text { fruit }\end{array}$ & - \\
\hline $\begin{array}{l}\text { Male } \\
\text { Age over } 65 \text { years } \\
\text { Unhealthy }\end{array}$ & Passion juice & $\begin{array}{l}\text { Passion juice with gac } \\
\text { fruit }\end{array}$ & Passion juice & $\begin{array}{l}\text {-Lingzhi drink } \\
\text {-Germinated brown hom nin rice drink } \\
\text { with cereal }\end{array}$ \\
\hline $\begin{array}{l}\text { Male } \\
\text { Age over } 65 \text { years } \\
\text { Healthy }\end{array}$ & Lingzhi drink with honey & $\begin{array}{l}\text { Mangosteen juice with } \\
\text { longkong }\end{array}$ & Lingzhi drink with honey & - \\
\hline $\begin{array}{l}\text { Female } \\
\text { Age 60-65 years } \\
\text { Unhealthy }\end{array}$ & Passion juice & Passion juice & $\begin{array}{l}\text { Passion juice with gac } \\
\text { fruit }\end{array}$ & $\begin{array}{l}\text {-Mangosteen juice } \\
\text {-Mangosteen juice with longkong } \\
\text {-Passion juice }\end{array}$ \\
\hline $\begin{array}{l}\text { Female } \\
\text { Age over } 65 \text { years } \\
\text { Unhealthy }\end{array}$ & $\begin{array}{l}\text { Passion juice with gac } \\
\text { fruit }\end{array}$ & Passion juice & $\begin{array}{l}\text { Passion juice with gac } \\
\text { fruit }\end{array}$ & $\begin{array}{l}\text {-Mangosteen juice } \\
\text {-Mangosteen juice with longkong } \\
\text {-Passion juice }\end{array}$ \\
\hline $\begin{array}{l}\text { Female } \\
\text { Age over } 65 \text { years } \\
\text { Healthy }\end{array}$ & Mangosteen juice & Mangosteen juice & $\begin{array}{l}\text { Mangosteen juice with } \\
\text { longkong }\end{array}$ & - \\
\hline
\end{tabular}

\section{ACKNOWLEDGMENT}

Apart of this project is also supported by the Agricultural Research Development Agency (Public Organisation) and King Mongkut's University of Technology North Bangkok, Thailand.

\section{REFERENCES}

[1] United Nations. (October 2017). World Population Prospects 2017. [Online]. Available: https://esa.un.org/unpd/wpp/

[2] Z. Długosz and P. Raźniak, "Risk of population aging in Asia," Procedia - Soc. Behav. Sci., vol. 120, pp. 36-45, March 2014.

[3] R. L. Divine and L. Lepisto, "Analysis of the healthy lifestyle consumer," J. Consum. Mark., vol. 22, no. 5, pp. 275-283, 2005.

[4] T. Luckow and C. Delahunty, "Which juice is "healthier'? A consumer study of probiotic non-dairy juice drinks," Food Qual. Prefer., vol. 15, no. 7-8, pp. 751-759, 2004.

[5] R. H. Sprague, "A Framework for the development of decision support systems," Source MIS Q., vol. 4, no. 4, pp. 1-26, Dec. 1980.

[6] W. P. Goh, X. Tao, J. Zhang, and J. Yong, "Decision support systems for adoption in dental clinics: A survey," Knowledge-Based Syst., vol. 104, pp. 195-206, July 2016.

[7] D. Prasad and S. Ratna, "Decision support systems in the metal casting industry: An academic review of research articles," Mater. Today Proc., vol. 5, no. 1, pp. 1298-1312, 2018.
[8] R. S. Magalhães, C. H. O. Fontes, L. A. L. D. Almeida, and M Embiruçu, "Identification of artificial neural network models for three-dimensional simulation of a vibration-acoustic dynamic system," Open J. Acoust., vol. 3, pp. 14-24, March 2013.

[9] Z. Liao, B. Wang, X. Xia, and P. M. Hannam, "Environmental emergency decision support system based on artificial neural network," Saf. Sci., vol. 50, no. 1, pp. 150-163, Jan. 2012.

[10] W. C. Chiang, D. Enke, T. Wu, and R. Wang, "An adaptive stock index trading decision support system," Expert Syst. Appl., vol. 59, pp. 195-207, Oct. 2016.

[11] O. W. Samuel, G. M. Asogbon, A. K. Sangaiah, P. Fang, and G. Li, "An integrated decision support system based on ANN and Fuzzy_AHP for heart failure risk prediction," Expert Syst. Appl., vol. 68, pp. 163-172, Feb. 2017.

[12] R. K. Boccorh and A. Paterson, "An artificial neural network model for predicting flavour intensity in blackcurrant concentrates," Food Qual. Prefer., vol. 13, no. 2, pp. 117-128, March 2002.

[13] A. Kengpol and W. Wangananon, "The expert system for assessing customer satisfaction on fragrance notes: Using artificial neural networks," Comput. Ind. Eng., vol. 51, no. 4, pp. 567-584, Dec. 2006.

[14] Á. Mulero, I. Cachadiña, and J. O. Valderrama, "Artificial neural network for the correlation and prediction of surface tension of refrigerants," Fluid Phase Equilib., vol. 451, pp. 60-67, Nov. 2017.

[15] P. Jiang and J. Chen, "Displacement prediction of landslide based on generalized regression neural networks with k-fold cross-validation," Neurocomputing, vol. 198, pp. 40-47, July 2016.

[16] X. Deng, Q. Liu, Y. Deng, and S. Mahadevan, "An improved method to construct basic probability assignment based on the confusion 
matrix for classification problem," Inf. Sci. (Ny)., vol. 340-341, pp. 250-261, May 2016.

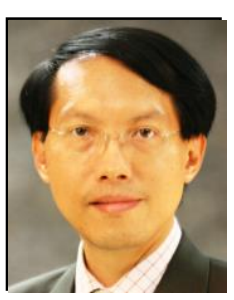

Athakorn Kengpol is professor of industrial engineering at the Faculty of Engineering, King Mongkut's University of Technology North Bangkok, Thailand. He received the $\mathrm{PhD}$ in manufacturing engineering and operations management from the University of Nottingham, UK and the DSc in industrial engineering and management from the Lappeenranta University of Technology, Finland. His research interests include artificial intelligent in decision support systems for cyber physical system, management information systems and packaging design.

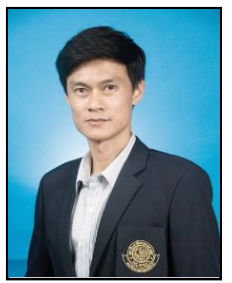

Jakkarin Klunngien received his master's degree in engineering (industrial engineering) from King Mongkut's Institute of Technology North Bangkok, Bangkok, Thailand in 2005. He has been employed under the position of lecturer in Industrial Engineering Department at Kasetsart University Sriracha Campus Currently, he is studying doctor of philosophy (industrial engineering) in Faculty of Engineering, King Mongkut's University of Technology North Bangkok, Thailand

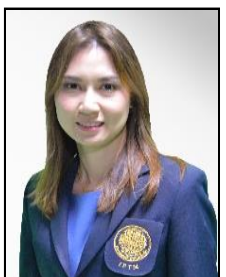

Sopida Tuammee is a lecturer in College of Industrial Technology, King Mongkut's University of Technology North Bangkok, Thailand. Her research interests include multimodal transportation and multiple criteria decision making (MCDM) 